\title{
Association between long travel and venous thromboembolic disease: a systematic review and meta-analysis of case-control studies
}

\author{
A. Javier Trujillo-Santos • Alberto Jiménez-Puente • \\ Emilio Perea-Milla
}

Received: 18 March 2007 / Accepted: 18 July 2007 / Published online: 26 September 2007

(C) Springer-Verlag 2007

\begin{abstract}
The term "economy-class syndrome" defines an infrequent episode of venous thromboembolism (VTED) related to a long travel, namely by plane. However, this relation has not clearly been demonstrated by investigators. We carried out a systematic review and a meta-analysis of cases-control studies that had studied this topic. We realised a systematic review of the literature and selected all the casecontrol studies published. Two authors carried out a methodological evaluation according to the Scottish Intercollegiate Guidelines Network items (concordance was analysed by weighted kappa index), and a systematic analysis of the potential biases of each study was assessed. We carried out the meta-analysis with the data extracted from the studies. We recovered eight cases-control studies. The relation between the antecedent of a long travel and subsequent VTED varied from $O R=1.1$ to $O R=4.0$ and was found to be significant in four studies. The studies were highly heterogeneous in methodology and so the results obtained about the relation between the long travel and the VTED and the score at SIGN50. Two meta-analysis were carried out: only with travels by plane in which the relation was not significant $(\mathrm{OR}=1.21$; CI 95\%, 0.95-1.55) and with all
\end{abstract}

\footnotetext{
A. J. Trujillo-Santos $(\bowtie)$

Paseo Alfonso XIII, s.n. 30204,

Cartagena, Murcia, Spain

e-mail: javiertrujillo@terra.es

\author{
A. Jiménez-Puente \\ Evaluation Unit, Hospital Costa del Sol, \\ Marbella, Málaga, Spain \\ E. Perea-Milla \\ Investigation Unit, Hospital Costa del Sol, \\ Marbella, Málaga, Spain
}

Department of Internal Medicine, Hospital Sta. Ma. del Rosell, types of transport, with a slightly significant relation $(\mathrm{OR}=$ 1.46 ; CI95\%, 1.24-1.72). We may deduce from this systematic review that there does exist a weak association between episodes of VTED and a long travel, but not by plane specifically. The heterogeneity and the methodological quality of the studies published preclude of more robust conclusions.

Keywords Venous thromboembolism · Long travel . Economy-class syndrome

\section{Introduction}

Venous thromboembolic disease (VTED) has been associated with many risk factors, one of which is the antecedent of a long travel, most often by plane. This association was previously suggested by Homans [1] and was believed so self-evident that it gave rise to the term "economy-class syndrome" [2]. Subsequently, the description of clinical cases related to other means of transport led to the coining of another more appropriate generic term, "traveller's thrombosis" [3].

The scenario for this syndrome has varied from the alarm caused by the apparently high frequency of fatal pulmonary embolism (PE) occurring after a prolonged flight, as reported in the media, to the scepticism of a weak, although likely association, reported in various scientific studies. The published reports have ranged from descriptions of individual cases to cohort studies and even clinical trials. However, the low incidence of episodes of VTED after a long travel makes the design of a case-control study particularly useful for evaluating the suggested association [4]. 
Our objective was to carry out a systematic review and meta-analysis of case-control studies to analyse the association between long travels and the development of VTED.

\section{Materials and methods}

We carried out a bibliographic search using a combination of keywords and MeSH headings in the Medline, Embase and Cochrane Library bibliographic databases. We selected only case-control studies, in any language, with no limit on the date of publication, and performed a cross search of the references cited in these studies. The corresponding author named in each study was requested to inform us of any relevant data that had not been described in the original manuscript.

Two authors (JTS and AJP) carried out a descriptive analysis of the studies identified in the search and evaluated their quality according to the checklist proposed by the Scottish Intercollegiate Guidelines Network [5]. Concordance in the evaluation of the items on this list was analysed using the respective weighted kappa indexes.

We also analysed the limitations and potential biases that might reduce the validity of the studies examined. The sources of bias analysed were grouped into three categories: exposure misclassification (recall bias), selection bias (including detection bias, effect misclassification, survival bias, self-selection bias and Berkson's bias) and confounding factors. Memory bias was defined as the fact that when subjects know they have suffered VTED, it makes them more likely to remember prior exposure to the antecedent of a long travel. Effect misclassification was minimised by considering only those studies in which VTED was diagnosed by objective complementary examination. Detection bias was suspected when the odds ratio (OR) in the days immediately after the travel was less than that corresponding to subsequent days. We only selected data published for VTED incidence at 30 days after the travel because was the time lapse most frequently analysed in the studies. Survival bias was considered to be that occurring when the study included prevalent cases, which could give rise to confounding of the variables related to the origin and those concerning the prognosis of the disease. Selfselection bias was considered to be present if the controls participated on their own initiative in the study and were not selected in a consecutive or random way; thus, they might be related to the results being sought. Berkson's bias would be derived from the use of hospital patients as controls.

The confounding factors were judged to be influential if no account were taken of the possibility that the exposure factor and the disease might be related through a third variable which was related to each of the other two.
From the results included in the published studies and the data supplied by the different authors, we were able to perform a meta-analysis of the studies that had estimated the risk ratio of deep-vein thrombosis (DVT) and of DVT and/or PE either after a travel (by any means of transport) or only after a travel by plane. The OR was used as a measure of association, with a confidence interval of $95 \%$. The hypothesis of homogeneity was evaluated using $X$ [2] and Der Simonian-Laird tests, and fixed and random effects methods were used, respectively, for the cases of homogeneity and heterogeneity between the studies. We assessed possible publication bias using Begg and Egger tests and carried out a sensitivity analysis by evaluating the influence of the absence of each individual study on the global measure of association of all the other studies.

The computer softwares used for this study were SPSS 11.5 (SPSS, Chicago, IL, USA) and EpiDat 3.1 [6].

\section{Results}

Nine case-control studies were recovered; of these, we analysed the data from seven [7-14], as the other one [15] corresponded to a preliminary analysis for one of the seven. One of these [7] was made up of three sub-studies, but for reasons of consistency, we only included the data for two of these in the meta-analysis, as in the third one, the authors assessed patients outpatients and inpatients with PE. Table 1 shows the main characteristics of all these studies. The relation between the antecedent of a long travel and subsequent VTED varied from $\mathrm{OR}=1.1$ to $\mathrm{OR}=4.0$ and was found to be significant in four studies $[8,9,11,14]$. In them, the OR ranged from $2.1(1.1-4.0)$ to $4.0(2.0-7.9)$.

With respect to means of transport, two studies [9, 12] only assessed travel by plane, while two [7] MEGA examined separately each means of transport. Another study [13] distinguished travel by plane from all other means of transport, while another two $[10,11]$ considered various means of transport jointly, but did not distinguish those corresponding to cases from controls, and in one study [8], any means of transport was eligible for consideration without further specification.

The duration of the travel was addressed in different ways: two studies $[8,12]$ made no reference to this question; two studies $[11,15]$ only considered travels with a duration exceeding $4 \mathrm{~h}$, and another, those exceeding $3 \mathrm{~h}$ [13]. The other three studies $[7,9,10]$ considered different durations. The lapse of time between the travel and the diagnosis of VTED was 2 weeks in one study [13] and 4 weeks for the others, except that of Samama et al. [8] which did not specify the period exactly and MEGA study [14] that included 8 weeks before. In the study by Dimberg et al. [12], two periods were 


\begin{tabular}{|c|c|c|c|c|c|c|c|c|c|c|}
\hline 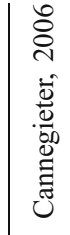 & 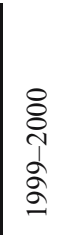 & 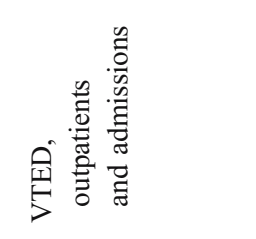 & 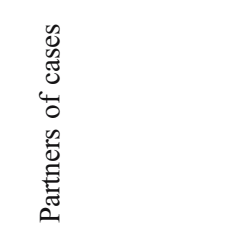 & 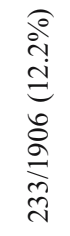 & 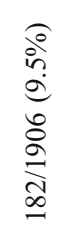 & 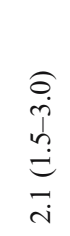 & $\frac{n}{\bar{\Xi}}$ & 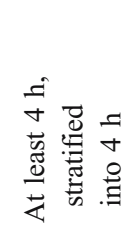 & $\infty$ & 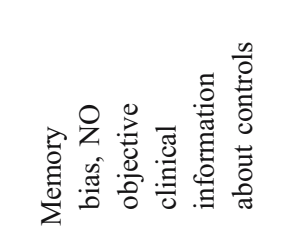 \\
\hline 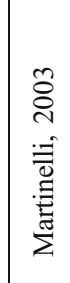 & $\begin{array}{l}\overrightarrow{8} \\
\text { ஸे } \\
\text { ळे }\end{array}$ & 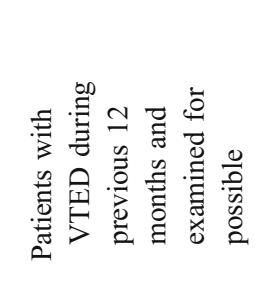 & 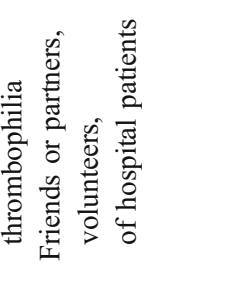 & 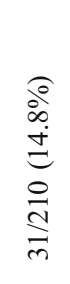 & 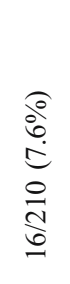 & $\begin{array}{l}\stackrel{\partial}{+} \\
\dot{+} \\
\stackrel{\Xi}{E} \\
\vec{i}\end{array}$ & $\begin{array}{l}0 \\
\frac{0}{0} \\
\frac{\pi}{2} \\
\frac{2}{0} \\
0\end{array}$ & 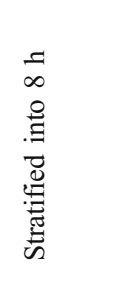 & $\nabla$ & 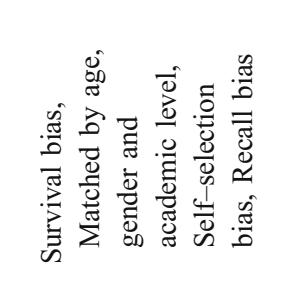 \\
\hline 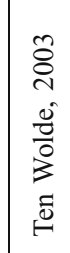 & $\begin{array}{l}8 \\
0 \\
\frac{1}{1} \\
\frac{1}{2}\end{array}$ & 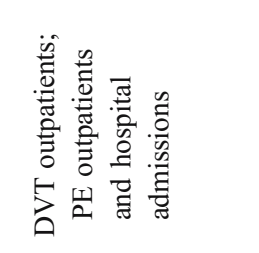 & 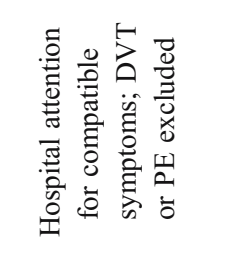 & 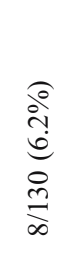 & 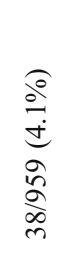 & $\begin{array}{l}\tilde{n} \\
\stackrel{n}{1} \\
\stackrel{e}{e} \\
\stackrel{0}{0}\end{array}$ & $\frac{\mathfrak{a}}{\stackrel{\Xi}{\sigma}}$ & 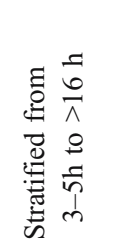 & + & 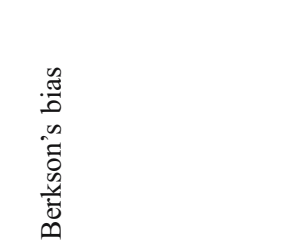 \\
\hline 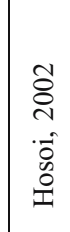 & 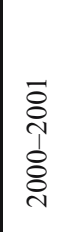 & 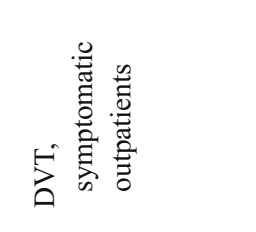 & 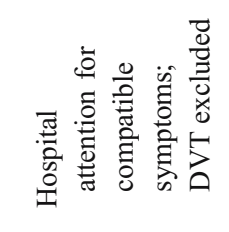 & 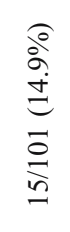 & 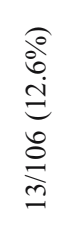 & 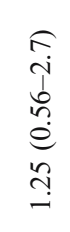 & 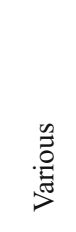 & 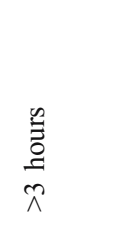 & $\sim$ & 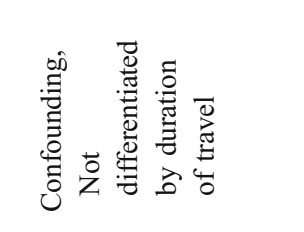 \\
\hline 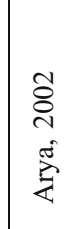 & $\begin{array}{l}\overrightarrow{8} \\
\stackrel{1}{1} \\
\stackrel{0}{0} \\
\text { ì }\end{array}$ & 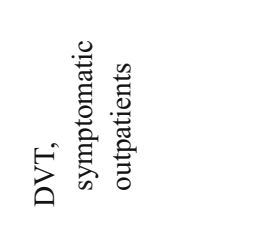 & 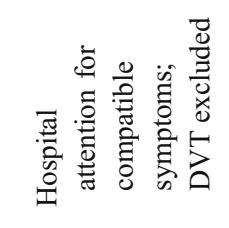 & 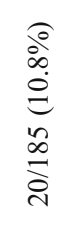 & $\begin{array}{l}\stackrel{a}{\stackrel{\infty}{\infty}} \\
\stackrel{\infty}{\infty} \\
\stackrel{\infty}{\infty}\end{array}$ & $\begin{array}{l}\tilde{n} \\
i \\
\infty \\
0 \\
e \\
j \\
\dot{j}\end{array}$ & 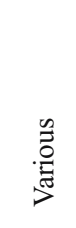 & 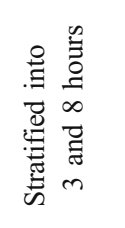 & $\nabla$ & 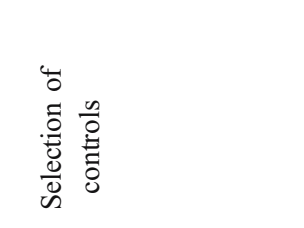 \\
\hline 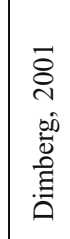 & $\begin{array}{l}\infty \\
\stackrel{\alpha}{a} \\
\frac{1}{2}\end{array}$ & 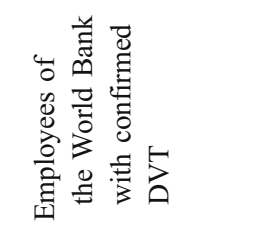 & 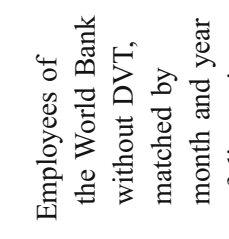 & 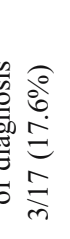 & 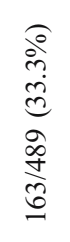 & $\begin{array}{l}\pi \\
I \\
I \\
e \\
\vdots \\
0\end{array}$ & $\begin{array}{l}0 \\
\frac{\tilde{I}}{2} \\
\text { 2. } \\
\text { ते } \\
0\end{array}$ & 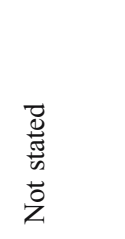 & $\nabla$ & 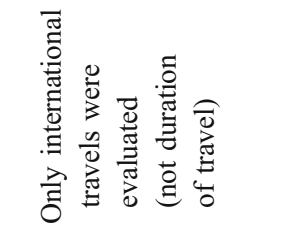 \\
\hline 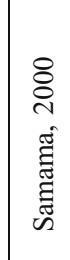 & $\begin{array}{l}\bar{a} \\
\bar{a} \\
2 \\
2\end{array}$ & 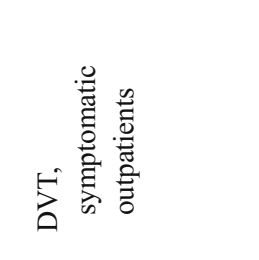 & 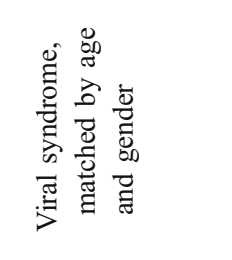 & 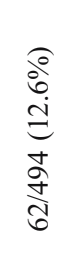 & 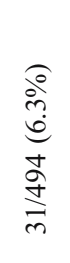 & $\begin{array}{l}\stackrel{f}{f} \\
\stackrel{i}{+} \\
\stackrel{\vec{i}}{i}\end{array}$ & 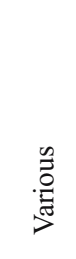 & 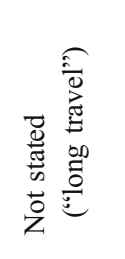 & $m$ & 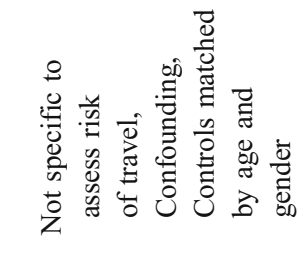 \\
\hline 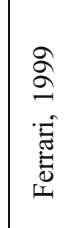 & 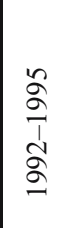 & 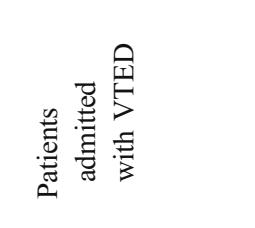 & 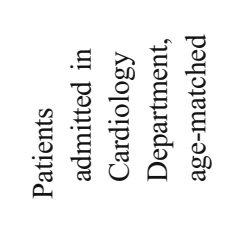 & $\begin{array}{l}\text { od } \\
\stackrel{+}{d} \\
\stackrel{d}{d} \\
\stackrel{8}{d} \\
\stackrel{i}{2}\end{array}$ & 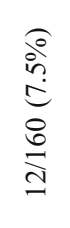 & $\begin{array}{l}\hat{\sigma} \\
\hat{j} \\
\stackrel{d}{d} \\
\circ \\
\dot{r}\end{array}$ & 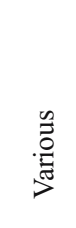 & 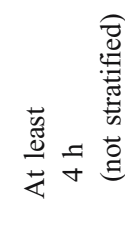 & $\nabla$ & 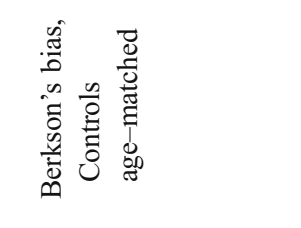 \\
\hline 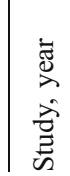 & 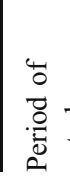 & 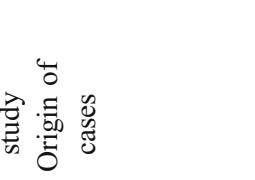 & 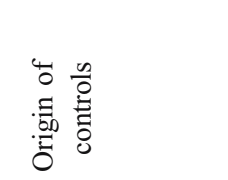 & $\begin{array}{l}4 \\
\dot{z}\end{array}$ & 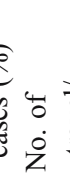 & & हैं & 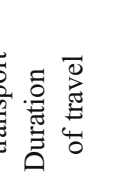 & & 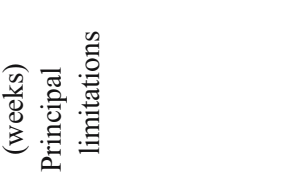 \\
\hline
\end{tabular}


analysed (15 and 30 days), but in our own analysis, only the data corresponding to 30 days were taken into consideration, this period being equivalent to the 4 weeks used in the other studies.

Four studies [7, 9, 11, 14] analysed cases of both DVT and of PE, while the others only considered patients with clinical presentation of VTED in the form of DVT. The selection of cases was generally that of patients with symptoms of DVT and/or PE. One study [12] used a register of days off work, kept by medical insurance companies for the staff of the company in which the study was carried out. The rate of prior history of a long travel, among the cases, ranged from $6.2 \%$ [7] to $24.4 \%$ [11].

Diverse methods were used for selection of controls. Three studies [7, 10, 13], selected outpatients who, after attending hospital with symptoms compatible with DVT and/or PE, were found not to have these diseases; in another study [11], the controls were hospital patients, matched by age, who had been admitted for other reasons during the same period of time as the cases. Two studies chose outpatient controls, matched by age and sex with the cases, one selecting patients with symptoms of respiratory viriasis [8] and the other using relatives and friends of patients who had suffered VTED [9]. Another study [14] chose the partners of the cases as controls. Finally, Dimberg et al. [12] chose ten control cases, matched by month and year of diagnosis of DVT, from among the staff of the same company that employed the cases. The study by Ferrari et al. [11] even used different exclusion criteria for cases and for controls such that anticoagulant treatment was an exclusion criterion for the former but not for the latter. The rate of prior occurrence of a long travel, among the controls, ranged from $4.1 \%$ [7] to $33.3 \%$ [12].

With respect to the possible biases present in each of the studies, we highlight the following:

- Recall or classification bias: the study by Martinelli et al. [9] could suffer from bias in this sense, as one of the exclusion criteria was the absence of a prior occurrence of VTED during the previous 24 months. In general, this bias is consubstantial with the studies of cases and controls such that the cases tend to relate the disease with the antecedent of interest.

- Detection bias: only one study [12] analysed two periods of time in which DVT had occurred after a long travel, namely at 15 and 30 days. The OR for the former period was greater than that for the latter, and thus, this form of bias was not present here.

- Misclassification bias: in all the studies, only cases of VTED that had been objectively diagnosed and for which the appropriate complementary examinations were taken into consideration, and thus, their correct classification was ensured. In three $[7,10,13]$, the controls were derived from persons who, having sought medical treatment for symptoms compatible with DVT and/or PE, were found not to suffer either of these after the same objective examination used to confirm the cases. In others, the controls presented no symptoms of DVT and/or PE and so were also assumed to be true controls.

- Survival bias: this bias type could have occurred in the study by Martinelli et al. [9], as the cases chosen were those patients who had suffered an episode of venous thromboembolism during the previous 2 years and for whom a study of thrombophilia was performed; thus, there was, in fact, a selection of all the potential incidental cases of DVT during this period.

- Self-selection bias: in the study by Martinelli et al. [9], the controls were recruited from the relatives and friends of the cases, a circumstance that could have negatively influenced the relation being studied, as the sample was obtained from a population that was socially related to the cases, and thus, exposure factors could have been shared. In MEGA study [14], the controls were partners of the cases, and the evaluated relation might have been diminished.

- Berkson's bias: this bias might have been present in the study by Ferrari et al. [11], as the controls chosen were patients admitted to hospital with chest pain, which could have meant they had a lower probability of prior travel; this pathology was, therefore, a potential limiting factor. Other studies [7, 10, 13] could also have been affected by this form of bias in that the controls they chose were patients who had attended hospital with symptoms compatible with those of DVT and/or PE; objective examination subsequently determined that neither pathology was present. The study by ten Wolde et al. [7] included cases of VTED present in patients who had been admitted to hospital for other reasons, which reduced the number of days before the episode of VTED in which the patient could have travelled.

The methodological evaluation of the studies is shown in Table 2. Overall, the evaluation was appropriate in five studies [7, 10, 12-14], while results were less satisfactory in three $[8,9,11]$ mainly because of the inadequate choice of controls and because the study design did not enable the authors to achieve a good estimate of the risk being studied. There was a high degree of agreement between the reviewers concerning the quality criteria of the cases and controls (weighted kappa index $=0.8$ ).

Results of the meta-analysis The studies were varied as regards the episode of VTED included (DVT and/or PE), the controls chosen, the means of transport evaluated and the estimated duration of the travels. These variations 
Table 2 Methodological evaluation of the studies included in the systematic review in accordance with SIGN 50 criteria

\begin{tabular}{|c|c|c|c|c|c|c|c|c|}
\hline Characteristic & $\begin{array}{l}\text { Ferrari } \\
1999\end{array}$ & $\begin{array}{l}\text { Samama } \\
2000\end{array}$ & $\begin{array}{l}\text { Dimberg } \\
2001\end{array}$ & $\begin{array}{l}\text { Arya } \\
2002\end{array}$ & $\begin{array}{l}\text { Hosoi } \\
2002\end{array}$ & $\begin{array}{l}\text { Ten Wolde } \\
2003\end{array}$ & $\begin{array}{l}\text { Martinelli } \\
2003\end{array}$ & $\begin{array}{l}\text { Cannegieter } \\
2006\end{array}$ \\
\hline \multicolumn{9}{|l|}{ Internal validity } \\
\hline Clear, appropriate questions & G & A & G & G & G & G & A & G \\
\hline \multicolumn{9}{|l|}{ Selection of subjects } \\
\hline $\begin{array}{l}\text { Cases and controls from comparable } \\
\text { populations }\end{array}$ & $\mathrm{A}$ & A & A-G & A-G & G & $\mathrm{A}$ & $\mathrm{P}$ & G \\
\hline $\begin{array}{l}\text { Identical exclusion criteria for cases } \\
\text { and controls }\end{array}$ & P-A & A & A & G & G & G & A & G \\
\hline Participation rate by cases and controls & $95-\mathrm{NS}$ & 80 & NS & NS & $74-79$ & NS & $91-\mathrm{NS}$ & $83-77$ \\
\hline $\begin{array}{l}\text { Comparison between participants and } \\
\text { non-participants }\end{array}$ & NS & NS & NS & NS & NS & NS & NS & NS \\
\hline $\begin{array}{l}\text { Cases are defined and clearly differentiated } \\
\text { from controls }\end{array}$ & A-G & $\mathrm{G}$ & $\mathrm{P}$ & A & G & $\mathrm{G}-\mathrm{A}$ & $\mathrm{P}$ & $\mathrm{G}-\mathrm{A}$ \\
\hline $\begin{array}{l}\text { It is clearly stated that the controls are } \\
\text { non-cases }\end{array}$ & A & G & $\mathrm{P}$ & $\mathrm{P}$ & $\mathrm{G}-\mathrm{A}$ & G-A & $\mathrm{P}$ & $\mathrm{P}$ \\
\hline \multicolumn{9}{|l|}{ Evaluation } \\
\hline $\begin{array}{l}\text { Knowledge of exposure did not influence } \\
\text { designation of cases }\end{array}$ & A & A & A & $\mathrm{P}$ & $\mathrm{G}-\mathrm{A}$ & $\mathrm{P}$ & A & A \\
\hline $\begin{array}{l}\text { The exposure is measured in a standard, } \\
\text { valid way }\end{array}$ & A & $\mathrm{P}$ & A-P & G-A & $\mathrm{G}-\mathrm{A}$ & G-A & $\mathrm{P}$ & A \\
\hline \multicolumn{9}{|l|}{ Confounding } \\
\hline Identification of main confounding factors & P-A & $\mathrm{P}$ & A & P-A & A & A-P & P-A & A \\
\hline \multicolumn{9}{|l|}{ Statistical analysis } \\
\hline Identification of confidence intervals & Yes & Yes & Yes & Yes & Yes & Yes & Yes & Yes \\
\hline \multicolumn{9}{|l|}{ Overall assessment } \\
\hline Control of bias and confounding factors & $+/++$ & $++/+$ & $++/+$ & $+/++$ & ++ & ++ & $++/+$ & ++ \\
\hline $\begin{array}{l}\text { Confidence that the overall effect is due to } \\
\text { the exposure being investigated }\end{array}$ & ++ & + & ++ & ++ & $+++/++$ & ++ & $++/+$ & ++ \\
\hline $\begin{array}{l}\text { The results are applicable to the target group } \\
\text { of patients being studied }\end{array}$ & ++ & + & $++/+++$ & +++ & $++/+++$ & +++ & ++ & +++ \\
\hline
\end{tabular}

A single evaluation is shown when the two reviewers agree; otherwise, both evaluations are given.

$G$ Good, $A$ adequate, $P$ poor, $N S$ not stated

influenced the performance of the meta-analysis. Thus, we decided to carry out two meta-analyses, on the basis of the similarity between study designs, i.e., on the one hand, studies of patients with DVT (with or without PE), considering any type of transport, and on the other hand, those studies examining only cases in which the subjects travelled by plane (Table 3 ).

Meta-analysis of studies including patients with DVT or $D V T+P E$, all types of transport Six studies [7, 8, 10, 11, 13, 14] were examined. The Der Simonian-Laird test of heterogeneity gave a result of $p=0.011$, with an estimated $75 \%$ total variance due to variance between the studies. The global estimator with a model of random effects produced an OR of $1.46(95 \% \mathrm{CI}, 1.24-1.72)$. No publication bias was recorded (the Begg and Egger tests results were not significant). The sensitivity analysis revealed that no study influenced significantly on the final OR. Figure 1a shows the forest plot graph corresponding to this meta-analysis.
Meta-analysis of studies including patients with DVT or $D V T+P E$, only travels by plane This meta-analysis included five studies $[9,10,12-14]$. The results of the Der Simonian-Laird heterogeneity test were not significant, which suggests there was little heterogeneity between the variances of the studies. The OR estimator produced a nonstatistically significant value of 1.21 (95\%CI, 0.95-1.55). Again, no publication bias was detected, and the sensitivity analysis showed that none study was influential on the OR. Figure $1 \mathrm{~b}$ shows the forest plot graph corresponding to this meta-analysis.

\section{Discussion}

The results from our analysis reveal a slight association between long travels and the development of DVT or PE, although this association disappears when only travels by 
Table 3 Results obtained in the studies, by type of transport

\begin{tabular}{|c|c|c|c|c|c|c|}
\hline & \multicolumn{2}{|c|}{ All types of transport } & \multicolumn{2}{|l|}{ Only plane } & \multicolumn{2}{|l|}{ Other types } \\
\hline & Cases & Controls & Cases & Controls & Cases & Controls \\
\hline \multicolumn{7}{|l|}{ DVT } \\
\hline Samama & $62 / 494(12.6)$ & $31 / 494(6.3)$ & NS & NS & NS & NS \\
\hline Hosoi & 15/101 (14.9) & $13 / 106(12.6)$ & 9/101 (8.9) & $12 / 106(11.3)$ & $6 / 101(5.9)$ & $1 / 106(0.9)$ \\
\hline Arya $^{a}$ & $20 / 185(10.8)$ & $31 / 383(8.1)$ & $16 / 185(8.6)$ & $29 / 383(7.6)$ & $4 / 185(2.2)$ & $2 / 383(0.5)$ \\
\hline Ten Wolde ${ }^{\mathrm{b}}$ & $8 / 130(6.2)$ & $38 / 959(4.1)$ & NS & NS & NS & NS \\
\hline Dimberg $^{\mathrm{c}}$ & NA & NA & $17 / 30(56.7)$ & 489/891 (54.9) & NA & NA \\
\hline \multicolumn{7}{|l|}{ DVT and/or PE } \\
\hline Ferrari & $39 / 160(24.4)$ & $12 / 160(7.5)$ & NS & NS & NS & NS \\
\hline Martinelli & NA & NA & $31 / 210(14.8)$ & $16 / 210(7.6)$ & NA & NA \\
\hline Cannegieter $^{\mathrm{d}}$ & $233 / 1906(12.2)$ & $182 / 1906(9.5)$ & $86 / 1906(4.5)$ & $72 / 1906(3.8)$ & $147 / 1906(7.7)$ & $110 / 1906(5.8)$ \\
\hline
\end{tabular}

$N A$ Not applicable, $N S$ not stated

Results are expressed as number of patients travelling / total (\%).

${ }^{a}$ Arya: Travels of more than $3 \mathrm{~h}$

${ }^{\mathrm{b}}$ Ten Wolde. Restricted to patients capable of travelling

${ }^{c}$ Dimberg: More specific case definition of the two analysed

${ }^{\mathrm{d}}$ Cannegieter: Venous thromboembolism episodes within the 8 weeks after travel

a

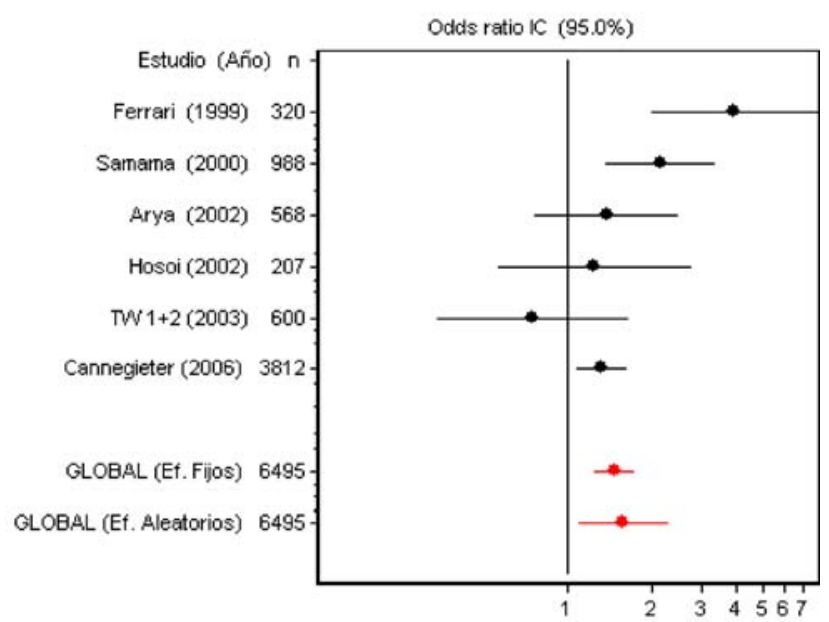

b

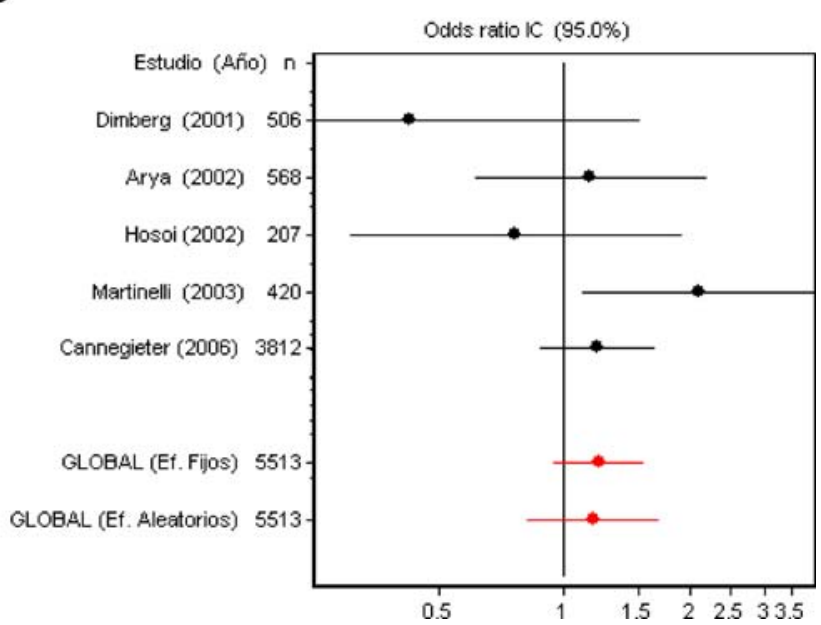

Fig. 1 Forest plot for studies that evaluated the antecedent of any type of transport and only travels by plane. a Travels by any type of transport. b Travels by plane plane are considered. The published case-control studies were characterised by considerable heterogeneity, especially in the selection of controls, and there were some errors in the study design that could have led to bias in estimating the effect of the association being studied. A meta-analysis of case-controls studies has recently been published. In that study, we did not find any relationship between a longdistance travel and venous thromboembolic disease when all the means of transportation were valued or only by plane, but not all published studies were included [14].

The pathogenic basis of the "economy class syndrome" lies in a series of predisposing environmental factors within aircraft (low humidity, relative hypoxia and low barometric pressure) that would facilitate the relative dehydration of passengers; these factors would be accompanied by mechanical ones, such as immobility, the narrowness of the seats and the prolonged maintenance of a seated position, with flexion and compression of the poplitea region [15-17]. The description of episodes of DVT related to other means of transport produces a loss of plausibility of the environmental factors associated solely with travels by plane and puts the prime focus on purely mechanical factors and on the characteristics of the patients themselves. Moreover, a recently published study [18] found no variation at all between different coagulation factors after exposure to the environmental conditions resembling in a prolonged travel by plane. Nevertheless, in one recent systematic review, Philbrick et al. [19] emphasised the presence of prothrombotic risk factors and a flight duration longer than $6 \mathrm{~h}$ as predisposing to suffer a VTE episode.

The patient-related variables refer to a greater frequency of VTED risk factors. Thus, various studies have reported that a high percentage of the patients involved were obese, 
higher or smaller, aged more than 50 years, had antecedents of VTED, were taking oral contraceptives or presented a state of hypercoagulability or thrombophilia $[2,11,15,18$, 19]. This result implies that there is a relation between transport-related factors and those concerning to the patients themselves, and that this is relevant to the development of an episode of VTED.

Studies that have sought to analyse this association have obtained divergent results mainly because of the different study designs; this would explain the high variability in the OR obtained, which ranged from 1.1 to 4.0. Moreover, these studies were heterogeneous in various methodological respects, and this could have influenced the final results; some $[8,11]$ matched the cases and controls by sex and age, which limits the influence of these variables in determining the association under study; in the study by Martinelli et al. [9], the cases were a selection of all the possible incident cases within a given period; in another [11], the controls selected were not derived from the same population as that of the cases; the means of transport and the duration of the travel, as well as the type of VTED episode evaluated were different in all the studies; and, in general, no multivariate or stratified analysis was carried out to attribute the increased risk of developing an episode of VTED to the long travel.

An interesting aspect from the methodological point of view is the possible selection bias that might have entered these studies: those patients (the cases) who travelled presented fewer VTED risk factors than did the controls, i. e. they were basically more healthy. Not only could this have led to the relation between the development of an episode of VTED and the antecedent of having made a long travel being underestimated, but it might even appear that the prior travel had a protective effect, as was the case in the study by Dimberg et al. [12]. One way of minimising this type of bias could have been to include only those patients who would physically have been capable of making a long travel; this was only actually done in the case of the study by ten Wolde et al. [7]. Another possibility could be to adjust for this variable (which might be considered that of comorbidity) by means of multivariate analysis.

Given the methodological heterogeneity of the published studies of cases and controls, it was not possible to carry out a detailed meta-analysis of different aspects of the relation under study, and so its scope was limited to those studies that assessed the association between DVT or between DVT and PE and prolonged travels by plane or by any other form of transport. In any case, the association that was found in the latter case was only weak, and there was a large degree of variation in the methodological quality applied in the various studies.

A noteworthy question is the antecedent of a prolonged travel made by the controls, with variations in all the studies of $6.3-8.1 \%$, except in the case of the study by Dimberg et al. [12]; in the latter case, the scenario chosen for analysis led to the choice of a population in which a high proportion $(33.3 \%)$ made international travels, an aspect that could have weakened any potential association. Similarly, the rate of incidence of a lengthy travel among the cases ranged from 6.7 to $14.8 \%$, although in two studies, this figure was surprisingly high, $17.6 \%$ in that by Dimberg et al. [12] and $24.4 \%$ in the study by Ferrari et al. [11].

The methodological quality of the studies examined in this systematic review means that we must be cautious concerning the results reported. Although there does seem to be a likely relation between a long travel and the development of an episode of VTED, such an association must be of such a magnitude that a small bias or modification to the study could increase or decrease the strength of the association recorded.

In conclusion, we may deduce from this systematic review that there does exist a real, but weak, association between episodes of VTED and the antecedent of a lengthy travel, and this relation with the travels by plane is only nearly significant. The heterogeneity and the methodological quality of the studies published on the question limit the robustness of the conclusions obtained.

\section{References}

1. Homans J (1954) Thrombosis of the deep leg veins due to prolonged sitting. N Engl J Med 250:148-149

2. Symington IS, Stack BHR (1977) Pulmonary thromboembolism after travel. Br J Dis Chest 71:138-140

3. Kesteven PL (2000) Traveller's thrombosis. Thorax 55(Suppl 1): S32-S36

4. Rothman KJ (1998) Modern epidemiology, 2nd edn. Little, Brown and Company, Boston

5. Scottish Intercollegiate Guidelines Network (2004) Methodology checklist 3: cohort studies. In: SIGN 50: a guideline developers' handbook. Edinburgh: The network. available: http://www.sign.ac. uk/guidelines/fulltext/50/checklist3.html (accessed 2006 Jan 22)

6. Epidat 3.1. Análisis epidemiológico de datos tabulados. Available: http://dxsp.sergas.es/ApliEdatos/Epidat/cas/default.asp (accessed 2006 March 01)

7. ten Wolde M, Kraaijenhagen RA, Schiereck J, Hagen PJ, Mathijssen JJ, Mac Gillavry MR et al (2003) Travel and the risk of symptomatic venous thromboembolism. Thromb Haemost 89:499-505

8. Samama MM for the Sirius Study Group (2000) An epidemiologic study of risk factors for deep vein thrombosis in medical outpatients: the Sirius Study. Arch Intern Med 160(2):3415-3420

9. Martinelli I, Taioli E, Battaglioli T, Podda GM, Passamonti SM, Pedotti P et al (2003) Risk of venous thromboembolism after air travel. Interaction with thrombophilia and oral contraceptives. Arch Intern Med 163:2771-2774

10. Arya R, Barnes JA, Hossain U, Patel RK, Cohen AT (2002) Longhaul flights and deep vein thrombosis: a significant risk only when additional factors are also present. Br J Haematol 116(3-I):653-654

11. Ferrari E, Chevallier T, Chapelier A, Baudouy M (1999) Travel as a risk factor for venous thromboembolic disease. A case-control study. Chest 115:440-444 
12. Dimberg LA, Mundt KA, Sulsky SI, Liese BH (2001) Deep venous thrombosis associated with corporate air travel. J Travel Med 8:127-132

13. Hosoi Y, Geroulakos G, Belcaro G, Sutton S (2002) Characteristics of deep vein thrombosis associated with prolonged travel. Eur J Endovasc Surg 24:235-238

14. Adi Y, Bayliss S, Rouse A, Taylor RS (2004) The association between air travel and deep vein thrombosis: systematic review \& meta-analysis. BMC Cardiovasc Dis 4:7

15. Cannegieter SC, Doggen DJ, van Houwelingen HS, Rosendaal FR (2006) Travel-related venous thrombosis: results from a large population-based case control study (MEGA Study). PLoS Med 3(8):e207
16. Kraaijenhagen RA, Haverkamp D, Koopman MMW, Prandoni P, Piovella F, Büller HR (2000) Travel and risk of venous thrombosis. Lancet 356(9240):1492-1493

17. Rege KP, Bevan DH, Chitolie A, Shannon MS (1999) Risk factors and thrombosis after airline flight. Thromb Haemost 81:995-996

18. Toff WD, Jones CI, Ford I, Pearse RJ, Watson HG, Watt SJ et al (2006) Effect of hypobaric hypoxia, simulating conditions during long-haul air travel, on coagulation, fibrinolysis, platelet function, and endothelial activation. JAMA 295:2251-2261

19. Philbrick JT, Shumate R, Siadaty MS, Becker DM (2007) Air travel and venous thromboembolism: a systematic review. J Gen Intern Med 22:107-114 